\title{
Heart perforation in patients with permanent cardiac pacing - pilot personal observations
}

Justyna Piekarz, Jacek Lelakowski, Anna Rydlewska, Jacek Majewski

Jagiellonian University, Collegium Medicum, Institute of Cardiology, Department of Electrocardiology, John Paul II Hospital, Krakow, Poland

Submitted: 15 November 2010

Accepted: 24 February 2011

Arch Med Sci 2012; 8, 1: 70-74

DOI: 10.5114/aoms.2012.27284

Copyright @ 2012 Termedia \& Banach

\begin{abstract}
Introduction: Heart perforation is a rare complication of pacemaker (PM)/implantable cardioverter-defibrillator (ICD) implantation.

Material and methods: In our clinic in 2005-2010, 6 patients with heart perforation were hospitalized ( 3 women, 3 men), mean age $58.6 \pm 20.8$ years (17 to 73 years). The indication to PM/ICD implantation was tachy-brady syndrome in 3 cases, second-degree atrioventricular block, advanced with losses of consciousness, vaso-vagal syndrome type II B with asystole lasting $12 \mathrm{~s}$ and recurrent non-sustained ventricular tachycardia in 1 patient. We analyzed patient's medical records, X-rays, echocardiography, computed tomography (CT) and procedure protocols.

Results: The incidence of heart perforation was $0.09 \%$. Symptoms developed 4 to 990 days (mean $186.3 \pm 394.3$ ) after PM/ICD implantation. The perforation site was found in the right atrial wall in 1 cases and the right ventricular wall in 6 cases. The TTE revealed an accumulation of fluid in the pericardium over $10 \mathrm{~mm}$ behind the posterior wall of the left ventricle in all patients. The CT scan confirmed perforation of the heart chambers (atrium and in 6 cases ventricle). In 5 cases the whole device was removed by direct traction or percutaneous lead extraction with pericardiocentesis when necessary (pericardium drainage in 3 cases) while in 1 case cardiac surgery was needed.

Conclusions: The perforating lead may be removed by direct traction in the operating room with cardiosurgical, anesthesiological and echocardiographical backup. In case of the lead perforation outside the pericardial sac or its atypical location, cardiac surgery is a safer method. The most important diagnostic method remains computed tomography.
\end{abstract}

Key words: heart perforation, pacemaker/cardioverter-defibrillator implantation.

\section{Introduction}

Implantation of a pacemaker (PM)/cardioverter-defibrillator (ICD), as well as reimplantation and repair operations, is associated with a low risk of complications, which usually occur early after the procedure. Possible complications include the following: PM pocket haematoma, stimulation of the chest wall muscle, diaphragm, phrenic nerves, lead dislocations within the heart, infections (bacterial endocarditis of the tricuspid valve, of the lead tip area, pacemaker pocket), subclavian vein thrombosis and/or its supplies, and in rare cases right ventricle or right atrium perforation with possible tamponade symptoms. The most common late complication is lead fracture, which requires its repair or removal. Another possible com-

\author{
Corresponding author: \\ Jacek Lelakowski MD, PhD \\ 30/64 Wybickiego \\ 31-302 Krakow, Poland \\ Phone: +48 504299 354, \\ +48 126142277 \\ Fax: +48 126332399 \\ E-mail: \\ jlelakow@szpitaljp2.krakow.pl
}


plication is PM dislocation under the skin (which may cause decubitus or even skin necrosis) and skin puncture by a lead or PM [1].

Heart perforation in patients after PM implantation is a rare but potentially fatal complication. It may involve large veins, atrial or ventricular walls or the coronary sinus. Perforations may be acute (up to $24 \mathrm{~h}$ after implantation, which may lead to tamponade or death), subacute, which occur up to 1 month after implantation, or chronic, which appear at a later time. Another classification distinguishes between early (symptoms occur up to 1 month after implantation) and delayed perforations. The estimated rate of this complication is $1 \%$ and depends mainly on the surgeon's experience [2-13]. Main risk factors are listed in Table I $[1,4,5]$.

The paper presents cases of life-threatening subacute heart tamponade and delayed perforations in patients after PM/ICD and atrial/ventricular lead implantation.

\section{Material and methods}

In our clinic in 2005-2010, 6 patients with heart perforation were hospitalized ( 3 women, 3 men), mean age $58.6 \pm 20.8$ years (17 to 73 years). In 2 of the patients, implantation was performed outside our clinic. During this period 3600 PM and 1007 ICD implantations were performed. Characteristics of the patient population are presented in Table II.

We analysed patients' medical records, physical examination, X-rays, echocardiography, computed tomography (CT) and protocols of the implantation procedures.

\section{Results}

In the present study, the incidence of heart perforation was $0.09 \%$. Symptoms developed 4 to 990 days (mean $186.3 \pm 394.3$ ) after device implantation. There was no case of acute heart tamponade/perforation up to $24 \mathrm{~h}$ after implantation. The perforation site was found in the right atrial wall in one case and the right ventricular wall in 6 cases (Figures 1-2). Ventricular leads were placed in the right ventricular outflow tract and in 1 case in the apex. Atrial leads were placed in the right auricle. Heart wall damage was caused by pacing

Table I. Risk factors of lead perforation

\begin{tabular}{|c|}
\hline I. Type of lead, mode of stimulation, lead tip location \\
\hline Temporary stimulation \\
\hline Atrial stimulation \\
\hline Active fixation \\
\hline $\begin{array}{l}\text { Defibrillator leads: } \\
\text { - Double spirals } \\
\text { - Number of shocks delivered } \\
\text { - Excessive length of the lead } \\
\text { - Small diameter of the lead } \\
\text { - High resistance (small tip surface) } \\
\text { - Apical position }\end{array}$ \\
\hline II. Propriety of the heart muscle \\
\hline Congestive cardiomyopathy \\
\hline $\begin{array}{l}\text { III. The elderly, women, patients with low body mass } \\
\left(<20 \mathrm{~kg} / \mathrm{m}^{2}\right)\end{array}$ \\
\hline $\begin{array}{l}\text { IV. Anticoagulation therapy and steroid use within } 7 \text { days } \\
\text { of implantation }\end{array}$ \\
\hline V. Chest trauma, especially soon after implantation \\
\hline
\end{tabular}

Table II. Characteristics of the patient population

\begin{tabular}{|c|c|c|c|c|c|c|}
\hline Parameter & Patient 1 & Patient 2 & Patient 3 & Patient 4 & Patient 5 & Patient 6 \\
\hline Age [years] & 70 & 73 & 67 & 60 & 65 & 17 \\
\hline Sex & Male & Male & Female & Female & Male & Female \\
\hline Tachy-brady syndrome & + & + & + & & & \\
\hline $\begin{array}{l}\text { Second-degree atrioventricular block, } \\
\text { advanced with losses of consciousness }\end{array}$ & & & & + & & \\
\hline $\begin{array}{l}\text { Vaso-vagal syndrome type IIB with } \\
\text { asystole lasting } 12 \mathrm{~s}\end{array}$ & & & & & & + \\
\hline $\begin{array}{l}\text { Recurrent non-sustained ventricular } \\
\text { tachycardia }\end{array}$ & & & & & + & \\
\hline Dual chamber pacemaker & + & + & + & + & & + \\
\hline Dual chamber ICD & & & & & + & \\
\hline Coronary heart disease & + & + & + & + & + & \\
\hline Arterial hypertension & + & + & + & + & + & \\
\hline Dyslipidaemia & + & + & + & & & \\
\hline Hyperthyreosis & & & + & & + & \\
\hline Diabetes mellitus & & + & & & + & \\
\hline Obesity & & + & & & & \\
\hline
\end{tabular}




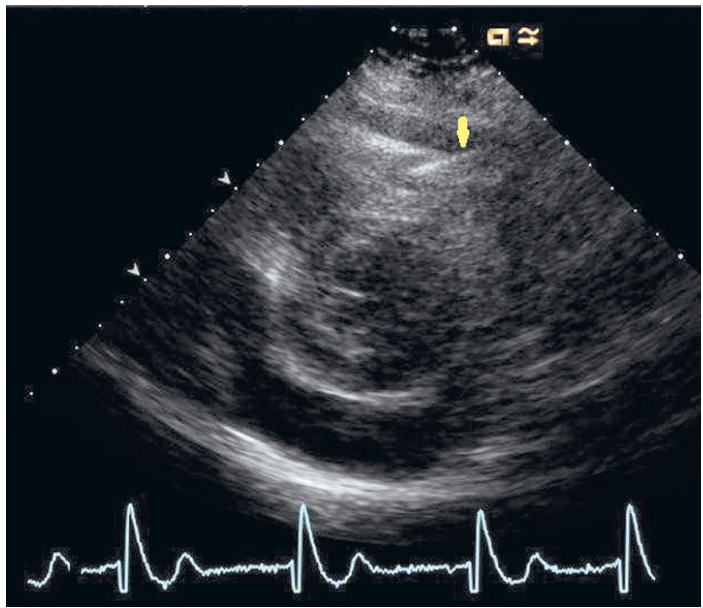

Figure 1. Transthoracic echocardiography view. Ventricular lead penetrating the wall of the right ventricle

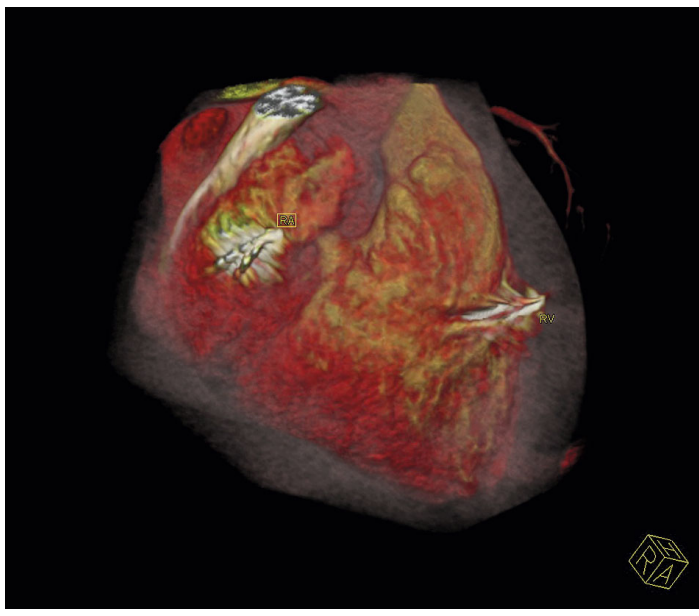

Figure 2. Computed tomography scan. Tips of both atrial and ventricular leads outside the heart

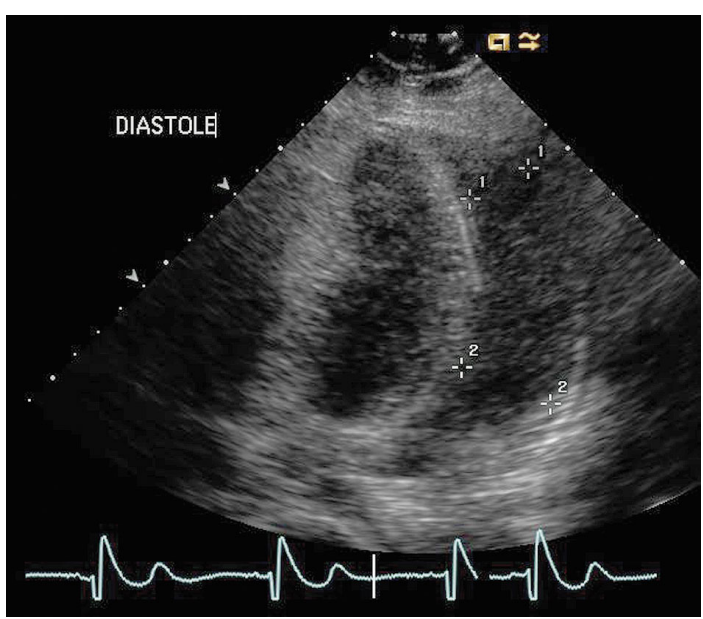

Figure 3. Transthoracic echocardiography view. Pericardial effusion up to $29 \mathrm{~mm}$ behind the left ventricular lateral wall

ventricular and atrial leads (Biotronik Setrox S60, S53, Vitatron Crystalline, Medtronic CapSureFixNovus) in 5 cases and by a 1-coil defibrillator lead (Medtronic Sprint Quattro) in one case. All leads were active fixation. Patients complained of stabbing pain in the left side of the chest, increased by movement (in 5 cases), dyspnoea (1 case), diaphragm stimulation (1 case), or remained asymptomatic (1 case). Standard follow-up of the electrical parameters showed pacing failure (in 4 patients), and sensing failure (in 6 cases). Transthoracic echocardiography showed pericardial effusion over $10 \mathrm{~mm}$ behind the posterior wall of the left ventricle in the parasternal long-axis view in all patients (Figure 3). Computed tomography scanning confirmed heart perforation (of the atrium and in 6 cases of the ventricle). In the operating room, with full cardiac surgery and anaesthesiology backup, the whole device was removed by direct traction, with pericardiocentesis when necessary (pericardium drainage in 3 cases) in 4 patients, and in one case (Figure 4) cardiac surgical extraction was used (in this patient, the lead penetrated the pericardial sac, injuring the parietal pleura and ended in the intercostal muscles, but without pneumothorax); 1 patient with delayed perforation underwent device removal by percutaneous lead extraction outside our department in a centre specializing in percutaneous lead extractions. Five patients had a new PM/ICD implanted, with lead tip location different from the previous one. One patient (patient no. 6) did not agree to have a new PM implanted.

\section{Discussion}

Heart perforation is a rare, but potentially fatal complication of permanent cardiac pacing systems. Subacute and chronic perforation may be asymptomatic, or it may cause dangerous symptoms resulting in death $[2,3,9,11,13]$. The common symptoms are chest pain, chest muscle or diaphragm contraction, hiccough, abdominal pain, dyspnoea, faintness or losses of consciousness (because of pacing failure), inadequate shocks of the ICD, symptoms of heart failure or tamponade $[2,3,9,12,13]$. Heart tamponade is a life-threatening complication, caused by rapid blood accumulation in the pericardial sac. It leads to pressure growth in the pericardium, which in turn impairs blood return to the atria and ventricles, lowering ejection volume and causing haemodynamic collapse with symptoms of cardiogenic shock, arrhythmias or death [10]. In our population, there was no case of an acute heart tamponade.

The most common perforation symptoms described in the literature are improper electrophysiological parameters; however, there have been cases with normal electrical function [1]. Failure of the lead to pace (increased pacing threshold) or sense (decreased $\mathrm{R}$ wave amplitude) or decreased lead impedance may suggest perforation and require further diagnosis $[5,7]$. In our material, in 

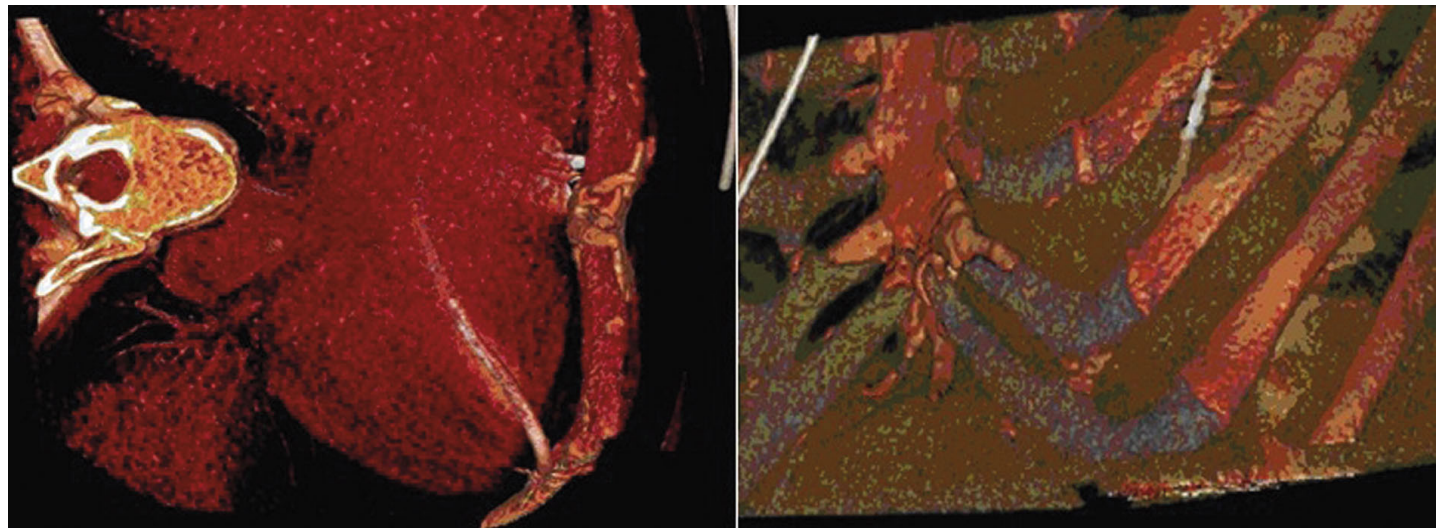

Figure 4. Computed tomography scan. Ventricular lead perforating pericardial sac, parietal pleura and ending in intercostal muscles

each case we observed a high pacing or sensing threshold.

Diagnostic methods in heart perforation involve chest X-ray and fluoroscopy (to show lead dislocation outside the border of the heart), transthoracic and transoesophageal echocardiography (TTE and TEE) (presence of the lead tip in the pericardium or pericardial effusion). The most important diagnostic method remains $\mathrm{CT}$, which is the gold standard. It reveals both lead dislocation and even small pericardial effusion $[4,9,12,13]$. Each of our patients had pericardial effusion.

In case of symptomatic heart perforation, the best method of treatment is extraction of the whole device. Various techniques of lead removal are used depending on the lead construction and the time since its implantation [5]. Active fixation leads of homogeneous diameter up to 2 years after implantation ( 6 months in the case of defibrillator leads) may be removed by direct traction, as in 4 of our patients. In case of failure, Byrd dilatators are used. Active fixation leads of uneven diameter and/or implanted over 2 years before or other lead types (passive fixation) and implanted over 1 year before (6 months in the case of defibrillator leads) should be removed by a classical set of Byrd dilatators [ 1 , $5,14]$, as occurred in our 1 patient with delayed perforation.

Most authors believe that patients with heart perforation should be transported to a centre specializing in percutaneous lead extraction and the best treatment is direct traction or percutaneous lead extraction in the operating room, with monitoring of basic life functions. Cardiosurgical, anaesthesiological and echocardiographic teams ready at hand are always necessary $[1,5]$. It is also advised to have TEE monitoring during and after the operation. Percutaneous extraction of the perforating lead, not requiring general anaesthesia, has been performed in cases of a very high operation risk.

American guidelines recommend surgical removal of the perforating leads $[6,8]$. The report- ed cases of surgical lead removal were digestive tract perforation, massive heart tamponade, and atypical location of the perforating lead in the intercostal muscles [9, 12], as in our patient who required cardiac surgical operation.

In most of these cases, a new pacemaker was implanted, placing the lead tip in a different location than before. In the case of open surgery, epicardial leads have been used [4].

Diagnosis should be based on the patient's medical records, telemetric control of electrical parameters and visual examinations. Computed tomography remains the gold standard and it confirmed perforation in all our patients.

The main limitation of this study is the small group: only 6 patients in 5 years. None of the above-mentioned predictors appeared in our patients with a significant frequency.

In conclusion, in case of symptomatic heart perforation, the best method of treatment is extraction of the whole device. The perforating lead may be removed by direct traction in the operating room with cardiosurgical, anaesthesiological and echocardiographic backup. In case of lead perforation outside the pericardial sac or its atypical location, cardiac surgery is a safer method. The most important diagnostic method remains $\mathrm{CT}$.

\section{References}

1. Byrd CL. Managing device-related complications and transvenous lead extraction. In: Clinical cardiac pacing, defibrillation, and resynchronization therapy. 3rd ed. Ellenbogen KA, Kay GN, Lau CP, Wilkoff BL (eds). W.B. Saunders and Elsevier Company, Fhiladelphia 2007; 855-966.

2. Laborderie J, Barandon L, Ploux S, et al. Management of subacute and delayed right ventricular perforation with a pacing or an implantable cardioverter-defibrillator lead. Am J Cardiol 2008; 102: 1352-5.

3. Haq SA, Heitner JF, Lee L, Kassotis JT. Late presentation of a lead perforation as a complication of permanent pacemaker insertion. Angiology 2008; 59: 619-21. 
4. Rydlewska A, Małecka B, Ząbek A, et al. Delayed perforation of the right ventricle as a complication of permanent cardiac pacing - is following the guidelines always the right choice? Non-standard treatment - a case report and literature review. Kardiol Pol 2010; 68: 357-61.

5. Kutarski A, Opolski G. PM/ICD lead extraction - most difficult and potentially hazardous electrotherapy procedure - logistic and training problems. Kardiol Pol 2010; 68: 736-42.

6. Lelakowski J. Indications for the procedure for transvenous removing of electrodes based on the guidelines of U.S. societies [Polish]. Pol Merkur Lekarski 2010; 165: 181-5.

7. Lelakowski J. Complications of permanent cardiac pacing as a rising challenge. Folia Cardiologica Excerpta 2009; 4: 69-72.

8. Wilkoff BL, Love CJ, Byrd CL, et al. Transvenous lead extraction: Heart Rhythm Society expert consensus on facilities, training, indications, and patient management: This document was endorsed by the American Heart Association (AHA). Heart Rhythm 2009; 6: 1085-104.

9. Adamowicz-Czoch E, Głowacki J, Hawranek M, Dziubek B, Gierlotka M, Zembala M. An old ventricular lead migration and subsequent dislodgement to the pleural cavity an unusual complication of permanent cardiac pacing [Polish]. Kardiol Pol 2008; 66: 869-72.

10. Banyś A, Bartczak K, Bitner M, Banach M, Jaszewski R. Cardiac tamponade with acute hypovolaemic shock induced by a right ventricular lesion during implantation of a PHILOS SR cardiostimulator and a SELOX ST 60 ventricular electrode - a case report. Kardiochirurgia i Torakochirurgia Polska 2010; 7: 88-90.

11. Selcuk H, Selcuk MT, Maden O, et al. Uncomplicated heart and lung perforation by a displaced ventricular pacemaker lead: a case report. Pacing Clin Electrophysiol 2006; 29: 429-30.

12. Greenberg S, Lawton J, Chen J. Images in cardiovascular medicine. Right ventricular lead perforation presenting as left chest wall muscle stimulation. Circulation 2005; 111: e451-2.

13. Khan M, Joseph G, Khaykin Y, Ziada K, Wilkoff B. Delayed lead perforation: a disturbing trend. Pacing Clin Electrophysiol 2005; 28: 251-3.

14. Lelakowski J, Kutarski A, Małecka B, Majewski J. Complex percutaneous extraction of a 15 -year-old atrial lead dislodged into the subclavian vein. Arch Med Sci 2011; 7: 164-7. 